on his eightieth birthday. His encyclopædic volume, "The Dispersal of Plants throughout the World", embodying many original observations, was published in 1930 when he was seventy-five. Commenting on his published work, one critic has said: "That there were inaccuracies goes without saying, but it was just that quality of recklessness in Ridley's work that enabled him to turn out such vast quan. tities of assimilable knowledge when it was most needed. A lesser man would have feared for his professional reputation, but Ridley was above such petty considerations. The work needed doing, and with the means at his disposal he did it magnificently".

Mr. Ridley was secretary of the Royal Asiatic Society, Straits Branch, during 1889-1911, and editor of its journal, in which he published many original papers. In 1905 he gave the first course of botany lectures to the newly formed King Edward VII College of Medicine, now the Medical School at the
University of Malaya, and continued these lectures until 1910.

Mr. Ridley was elected a Fellow of the Linnean Society in 1881 and of the Royal Society in 1907. His services were recognized by the honour of a C.M.G. in 1911. His work as a naturalist and in establishing the Para rubber industry has been recognized officially by various scientific and industrial bodies. We are planning appropriate celebrations at the Botanic Gardens, Singapore, on his hundredth birthday, which will include an exhibition of "Ridleyana".

It is my fervent hope that the Singapore Botanic Gardens may long continue as a leading centre of research in tropical botany and a worthy memorial to Mr. Ridley and all that he has done for us during his long and productive life. I am sure that readers of Nature will join with $m \theta$ in congratulating $\mathrm{Mr}$. Ridley on the present happy occasion of his centenary and in wishing him "Many Happy Returns".

\title{
THE ROYAL SOCIETY
}

\section{ANNIVERSARY ADDRESS* BY LORD ADRIAN, O.M., P.R.S.}

\section{AWARD OF MEDALS, 1955}

\section{Copley Medal : Sir Ronald Fisher, F.R.S.}

$\mathrm{T}$ HE rise of quantitative biology, which has been so noteworthy a feature of this century and especially of the past thirty years or so, has been due above all to the work of R. A. Fisher. The variability of living things posed problems and raised difficulties in the interpretation of experimental and observational data which made necessary something beyond the methods of the physical sciences. They required in fact a new approach to inductive inference, and one which would provide means of drawing conclusions of assessable reliability from variable material often available only in small samples. It is to Fisher's combination of mathematical skill and biological insight that we owe the developments, both theoretical and practical, which have done so much towards solving this problem and so making biologists of virtually every kind quantitative in their experiment, their analysis, and, most important of all, their thought.

Faced with the agronomical problems of Rothamsted, the staff of which he joined in 1919, Fisher began the remarkable series of statistical investigations which gave us the techniques described in "Statistical Methods", the tabular matter of "Statistical Tables" (published with F. Yates) for facilitating their use, and the philosophy of "Design of Experiments" by which they may be understood, appreciated and extended. The outcome has not merely stood the test of time in those branches of biology with which Fisher was immediately concerned, but also has had an ever-widening influence which now extends even beyond the borders of biology itself. In building the new biometry, Fisher has given especially to the younger biologists a confidence and quantitative

* Delivered at the Royal Society on November 30. outlook the full effect of which we have still to see.

While Fisher will always be associated chiefly with these developments in statistics and biometry, it should not be forgotten that he has made outstanding contributions in the field of geneties and evolu. tion. He set us on the way towards the modern study of biometrical genetics, and his mathematical treatment of natural selection has provided the basis for much of our present studies of populations. His theory of the evolution of dominance introduced us to the notion of the modification by selection of gene expression, and we owe primarily to him the theory by which we came to understand the working of the Rhesus blood groups. He has indeed long been established internationally as well as nationally as one of our leading geneticists, than whom few have done more to further the understanding of evolutionary processes.

\section{Royal Medal (A): Sir Alexander Todd, F.R.S.}

Over a wide field, Todd has made distinguished original contributions to the chemistry of natural products, more particularly in the field of compounds of physiological importance. His remarkable contributions to knowledge and his brilliance as an investigator have been recognized internationally by both organic chemists and biologists.

Todd joined Sir Robert Robinson in 1931 and plaved an important part in investigations on the synthesis of anthocyanins. His earlier work included major contributions in the field of vitamin chemistry, for example, in relation to the development of the structure of vitamin $B_{1}$, and to its synthesis. Independent of Karrer and Fernholz, Todd established the structure of vitamin $\mathrm{E}$ and achieved a synthesis. More recently, he has turned his attention to the vitamin $B_{12}$ group, and his degradative and synthetical 
studies have recently made fundamental contributions to our knowledge of the nature of these substances.

Undoubtedly Todd's most outstanding work in organic and biochemistry is in the nucleic acid field. Inter alia, he has developed rational methods for the synthesis of natural purine and pyrimidine nucleotides and for their phosphorylation to the nucleosides, including a synthesis of adenosine diphosphate and adenosine triphosphate. These results, among many others, have been achieved by a combination of theoretical knowledge and great experimental skill, aided by modern techniques.

Todd has been a pioneer in the chemistry of cannabinol, a series of complex bis-isoquinoline alkaloids, insect pigments (especially the colouring matter of Aphidae), kousso, and natural tropolones of mould origin.

Todd is a most capable investigator ; he has made fundamental contributions to organic and bio-chemistry and is recognized as a leader in these fields.

\section{Royal Medal (B) : Prof. V. B. Wigglesworth, C.B.E., F.R.S.}

Prof. V. B. Wigglesworth has increased our knowledge of almost every branch of insect physiology, and in most cases his work has formed the starting point for other investigators. His contributions to the understanding of those interwoven subjects-growth and cuticle structure-are of paramount importance. It was Wigglesworth who first resolved the epicuticular layer into its four components, showing both the chemical composition and the biological role of these layers, and we owe to him our knowledge of the structure and functioning of the dermal glands. But the formation of the cuticle is inseparable from the study of growth, and following Kopec's first demonstration that hormones were involved in the growth process, the rest of this vast and complex subject belongs to Wigglesworth: the hormonal balance giving rise to nymph or adult, the individual fields of organization in the epidermis, the mechanism of the parallel case of wound healing, and most recently, the way in which various hæmocytes enter into the process.

In the study of respiration, too, Wigglesworth has been a pioneer, and his recent studies on the migration of tracheoles and the effects of low oxygen tensions on tracheal organization have altered our entire concept of this subject.

$\mathrm{He}$ has done fundamental work on the digestion of blood meals by parasitic insects, and has demonstrated the formation of a peritrophic membrane in many species by secretion through an annular press. The detailed picture of the histological and chemical cycle of excretion through Malpighian tubules, and the secretory balance of salts and water in mosquitoes are also noteworthy.

From the width of the field covered by his numerous researches, it can be said that Wigglesworth is the 'father' of insect physiology. He has realized the potentiality of the insect as a medium for physiological research, and carried that view into practice with a mastery of observational and experimental methods.

\section{Davy Medal : Prof. H. W. Melville, F.R.S.}

Prof. H. W. Melville occupies a prominent position among those who have developed the extremely important field of the chemistry of macro-molecular substances. He has made many valuable contributions to the study of the mechanisms of the reactions in which such substances are formed, and has devised new experimental methods for the purpose. His early work on the examination of the various explosion limits in mixtures of phosphorus vapour and oxygen confirmed and extended important results bearing on the early development of the theory of chain reactions, especially the role of diffusing atoms and radicals. With the discovery of deuterium he examined a number of reactions in which the replacement of hydrogen by deuterium contributed to the elucidation of the mechanism. His work on photochemical reactions sensitized with mercury vapour greatly advanced and clarified this problem.

With this background Melville took up the study of the more complex processes of polymerization and to this field he has made important and lasting contributions. He devised new techniques for the study of the elementary processes which make up the overall chain reaction, and he applied the device of the rotating sector to the determination of the life-time of transient entities. This work has formed the basis of the quantitative study of free-radical reactivity both for polymerization and oxidation systems and in many other reactions. Melville and his collaborators have also made valuable contributions to the methods of synthesis and study of new polymeric systems, including recently the interesting group of 'black polymers'.

Melville's achievements have contributed much to our knowledge of the intricacies of chemical change, and his development of new methods and techniques for research have had an influence far beyond the confines of his own laboratory.

\section{Sylvester Medal : Prof. E. C. Titchmarsh, F.R.S.}

E. C. Titchmarsh's early work was in the theory of Fourier series and integrals. From this he passed on to a profound study of the special properties of the Riemann zeta-function, a subject which he made very much his own over a period of many years. His systematic use of Fourier integrals, and in particular of Parseval's formula, led to formulæ that would not have been suggested naturally by other methods, and these formulæ proved to be remarkably fruitful for the development of new properties of the function.

Some of his work on the order of magnitude of the zeta-function was based on developments of methods of estimating trigonometrical sums, due originally to Weyl and van der Corput. He applied these ideas to other problems also, and in particular he effected significant improvements in the estimation of the error terms in lattice point problems by extending van der Corput's method to double trigonometrical sums.

His more recent work has been in the field of eigenfunction expansions associated with second-order differential equations.

Prof. Titchmarsh has also written a number of important treatises on the various fields within which he has worked.

\section{Hughes Medal : Prof. H. S. W. Massey, F.R.S.}

Prof. H. S. W. Massey has added greatly to our knowledge of collision processes between electrons, neutral particles and ions. His early work was concerned with elastic and inelastic collisions between electrons and atoms. With Bullard he was responsible for some of the early experiments demonstrating 
diffraction effects. He carried out and directed a large number of detailed calculations, and, in particular, he exploited the variational method with great thoroughness, and did much to give a pattern to the experimental results by emphasizing the significance of the near-adiabatic conditions.

He was the first to apply the theories of attachment and recombination to problems of the ionosphere, and he led the way in reviewing the results of the radio experimenters and in trying to explain them. The difficulties in the way of explanation led him to investigate and discuss a wide range of atomic and molecular processes possible in the upper atmosphere. His work, and that of his pupils, is far in advance of any other in this field and has revolutionized our ideas about atomic processes in the ionosphere.

Prof. Massey is also the joint author of two important books on the subject of "Atomic Collisions" and of "Electronic Impact Phenomena".

\section{FUNCTIONS OF THE ROYAL SOCIETY}

A Royal Medal was awarded ten years ago to Sir Edward Salisbury for his contributions to botanical science. To-day if there were an appropriate medal we ought to give it to him for his contributions in a wider field, as Biological Secretary of the Royal Society. His term of ten years ends at this meeting. We shall all miss the wise counsel he has given the Society, and I count myself extremely fortunate to have held office with a colleague who has endeared himself to Officers and Fellows alike by his kindly understanding of our needs.

We rely on our Secretaries for much more than the supervision of moetings and publications, for they are constantly surveying our activities and must see to it that they are adapted to changing needs. Sir Edward's initiative has widened the scope of our meetings, he has maintained and extended our role in relation to the Commonwealth, and in the field of publications his care in the administration of the Parliamentary Grant-in-Aid has been largely responsible for the improved position enjoyed not only by ourselves but also by many other societies as well.

On behalf of the Society, therefore, I thank Sir Edward Salisbury for the valuable service he has rendered to science during his tenure of office as Biological Secretary.

The past year has seen a development in scientific activity which may have great consequences for all of us and I shall deal with it now because we are fortunate in having evidence of it at this meeting. I refer to the striking change which has come about in the field of international scientific effort. We have witnessed at Geneva a conference on the use of atomic energy at which the experts from every country could exchange information in the atmosphere of genuine scientific co-operation. The geophysicists, astronomers, meteorologists and geographers of every nation have already taken the first steps in their combined operations for the International Geophysical Year, and our own advance party, led by Surgeon Lieutenant-Commander Dalgliesh, is already on its way to the Antarctic, which is to be the scene of so much activity in 1957. In the less remote parts of the world, scientific delegations are now exchanging visits with an unaccustomed freedom, and we ourselves have been honoured by the visit of the
President of the U.S.S.R. Academy of Sciences and his colleagues during the past fortnight and by their presence at our Anniversary Moeting to-day.

We ought to think of our future rather than our past, but this is an occasion when we cannot be blamed for recalling our long history. When Peter the Great was in London at the end of the seventeenth century, he may well have attended some of the Society's meetings, but unfortunately the names of our visitors then were not recorded. In 1714, however, his fellow-countryman, Prince Alexander de Menzikoff, was admitted a Fellow of the Society, and the notice of his election was signed by our president, Sir Isazc Newton.

When we turn to the record of scientific achievements in the past year it is more difficult to select those which would really justify the use of that overworked epithet 'outstanding'. 'The passenger who is driven in a modern car along an open road will expect the milestones to recur every minute and will feel that something has gone wrong if they do not. In the past year nothing has gone wrong with the progress of scientific research, in fact the pace is faster than ever; but we are already so used to it that we have come to think more of the danger signals than of the milestones. It is, of course, unfortunate that knowledge can be dangerous, and it would certainly be a disaster if this became an excuse for preferring ignorance; but the danger signals have already attracted world-wide notice and the Society will not need to be reminded of them.

The milestones may have attracted less notice than they deserve: each of us can think of important advances in the field he knows best; but there are two which deserve mention now because our own Fellows have made them and because they are signs of what is likely to be a new phase in our understanding of Nature. I refer to the recent elucidation of the structure of two highly complex molecules, those of insulin and of vitamin $B_{12}$. Both these substances are formed in living cells and play an important part in the vertebrate economy, insulin in sugar metabolism and $B_{12}$ in the formation of the blood cells. Their existence has been known for many years, the use of the naturally occurring products has already saved a great many lives, and there is no immediate prospect of replacing the natural product with one made synthetically. But both are composed of very large molecules with a structure which has presented formidable problems to the chemist, and the solution of these problems cannot fail to enlarge our understanding of biochemical events.

The insulin molecule has a weight of more than 5,000 , with two polypeptide chains of unequal length linked by sulphur groups : it has taken Dr. F. Sanger and his collaborators more than ten years to map the entire structure. The molecule of $\mathrm{B}_{12}$ has one atom of cobalt and sixty-three of carbon. Dr. Dorothy Hodgkin's X-ray analysis of the crystals has been a remarkable demonstration of the value of this method for mapping such complex molecules: another example of the same thing has been the research on hæmoglobin which Dr. M. Perutz has carried out at the Cavendish Laboratory under the inspiration of Sir Lawrence Bragg, and on the other hand, we have Sir Alexander Todd's studies of the $\mathrm{B}_{12}$ group and of the nucleo-proteins, as well as Sanger's of insulin, to show that the organic chemist has not yet lost the power to work out his own salvation by classical methods. 
The structural formulæ of these molecules seem terribly elaborate to those of us who are not within the pale. We can applaud such triumphs of chemistry; but they forco us to realize how much the living cell must depend on the interplay of very large molecules in which the detailed arrangement of the atoms is of truly vital importance. We may wonder how many such elaborate structures will have to be mapped before we can see the way to general principles; though we are glad to have passed the stage when all that was known of the biochemistry of protoplasm was contained in the two words 'anabolism' and 'catabolism'.

At all events, since the difficulties now are largely technical, it is a comfort to know that the attack on one technically arduous problem has always made it far easier to deal with others of the same order. The successful mapping of large molecules has needed courage and persistence as well as imagination; but the way to further maps will be made plainer. It is a comfort, too, to know that we can confidently expect the unexpected, the advance which may give these problems a new turn. Yet in spite of that, the biologist has little hope of escaping the immense variety of his material. Even when the molecular structures are mapped there will be the organisms to deal with, the vast range of plant and animal form and in the end the differences between one man and another.

Biology, however, is not the only field where there are large territories to be explored in detail before we reach the next eminence. In fact the present course of progress in natural science, rapid though it is, does not suggest that scientific research is likely to change its present specialized character. The regions to be covered become greater and greater, and most of them can only be dealt with by the particular group of experts who know their way into the area.

This brings me back again to an appropriate theme for our annual meeting, namely, the part which the Royal Society should play to fulfil its task of improving natural knowledge.

At the end of his term of office, it is to be expected that your President will have ceased to marvel at his presumption in accepting so exalted a position and will have had time to consider its responsibilities. He will not have had much time, for the work of the Society grows apace; but in spite of that the duties of the President are certainly less arduous than most people might suppose. He is supported at every turn by the knowledge of a great Society at his back and by the Council and the whole staff at Burlington House inspired by an Assistant Secretary with a genius for tactful and effective administration. In fact, the President is so well eared for that it is a wise regulation which sets a limit to his reign.

Fellows will not need to be told of the many fields of activity in which the Royal Society is now engaged. It dispenses grants, awards medals, publishes journals and holds its scientific meetings; but I am convinced that the most important thing it does now is to exist and to perpetuate its existence by electing new Fellows.

Our meetings and periodicals are no doubt the best evidence of our existence; but they are scarcely essential to it. Indeed, their scope needs constant adjustment if they are not to be submerged in the present flood of scientific activity. Every subdivision of science has now begun to organize its special conferences and lectures. With so many subdivisions and so much to publish, the customary medium for printed communications is either a journal devoted to one spocial field or one which will take the shorter papers and publish them with the least delay. I am not suggesting that our own meetings and journals could be abolished without great loss, but rather that we should continue our policy of arranging some meetings where the specialist is encouraged to state his case before an audience of fellow scientists who are not all fellow specialists. That is certainly an important task.

In electing new Fellows, however, we perform a task which becomes more and more important as natural science expands and subdivides. It is essential to its progress here that there should be a council of scientists of acknowledged reputation able to form an impartial judgment on the claims of every field and on the merits of those who work in them. Scientific issues are now of great concern to those who frame the laws and policy of the State, and there must be some independent body to advise on them.

Statesmen and lawgivers are not likely to need advice on the latest developments of scientific thought; if they were, they might get better advice from the younger generation who have been trained in modern ideas and techniques and are used to the present scale of laboratory work. What is needed, however, is not an academy to pronounce on the controversial points of scientific theory but one with a reasonable knowledge of the dircetion in which research is leading.

We as a Society have never aspired to an organized control of scientific research : even in times of grave national emergency, we have preserved our status as a private body willing to co-operate with the State but unwilling to forfeit our independence. It is, of course, true that the Fellows of the Society have always played a large part in directing research into fruitful channels; but they have done so as heads of laboratories, teachers and leaders of research teams. It is true also that we control funds entrusted to us by past benefactors and that many of these funds must be used for the furtherance of particular branches of science. The value of the funds we hold now amounts to more than a million pounds, and we have also to administer yearly government grants of more than $£ 50,000$ for aiding scientific research, scientific publications and international activities. These sums, however, are small compared with the total which must be spent annually by any country dependent on machinery, and with the political system of Great Britain it seems far better for the Royal Society to keep itself outside the State organization. The larger this becomes, the more important will it be for us to maintain our status as an independent body of scientists whose chief obligation is the advancement of knowledge.

It is neither necessary nor desirable for the Society to give any official ruling on scientific issues, for these are settled far more conclusively in the laboratory than in the committee room. This principle has been recognized by the Royal Society since its foundation and it is stated specifically in the advertisement to the Philosophical Transactions in 1753 . This points out "that the certainty of the facts and the propriety of the reasonings contained in the several papers so published must still rest on the credit and judgement of their respective authors". The advertisement goes on to say "that it is an established rule of the Society, to which they will always adhere, never to give their opinion as a Body upon any subject either of Nature or Art, that comes before them". To make the position almost painfully clear, the advertisement goes on: "And therefore the thanks which are 


\section{No. 4493 December 10, $1955 \quad$ N A T U R E}

frequently proposed from the chair, to be given to the authors of such papors as are read at their accustomed meetings, or to the persons through whose hands they have received them, are to be considered in no otber light than as a matter of civility, in return for the respect shown to the Society by those Communications".

This stern insistence on our impartiality has not prevented us from issuing reports from time to time when the occasion seemed to demand them. There are, for example, the reports of the Food Committee during the First World War. But it has never been suggested that the Society assumed any other responsibility than that of choosing the committee of experts to draw up the report.

That, however, is the kind of obligation which the Royal Society should be specially fitted to discharge. It is right that the State should obtain the best scientific advice on practical issues, and it must know where to turn for the best panel of advisers. There are, of course, numerous societies to deal with particular fields, and some of these would be just as competent to nominate experts from their membership. But the fragmentation of science has left disputed borderlines as well as unclaimed territory, and if our Fellows have been properly chosen we should be able to justify the claim to represent all branches of science at the highest available level. Although we do not pronounce officially on matters of scientific controversy, we can say who are the leaders in any field and we know what sort of people they are.

If this were our only, or our principal, function it might seem to reduce our status to that of a scientific employment agency; but the applications of science are now of such consequence that the State must be forced to spend more and more of its income on science and technology. With scientists in short sup. ply it must expand research, teaching and development. It must be eareful not to harness too many active investigators to desks in Whitehall or to the committee rooms of universities, yet its administration must show an understanding of scientific needs. We cannot blame government departments and Ministers for mismanaging scientific affairs if we are unwilling to assume our responsibility for aiding them.

How far then does our constitution and our present practice fit us for such responsibilities? This year marks the death two hundred years ago of a great political scientist, the Baron de Montesquieu, a Fellow of the Royal Society who was renowned in every country for his analysis of the principles of government. Montesquieu came to us from France and was impressed by the precautions against autocracy inherent in the British constitution. It is true that his praise of the liberal form of government developed in Britain was linked with the suggestion that the weather had a great deal to do with it. He says : "In a nation so distempered by the climate as to have a disrelish of everything, even of life, it is plain that the government most suitable to the inhabitants is that in which they cannot lay their uneasiness to a single person's charge". But his analysis of our laws made him conclude that we were, or at all events had the opportunity to be, the freest country in the world and that it is in our nature to defend our liberties from autocratic control.

I do not think our procedure for the election of new Fellows could be made more representative than it is now. It may not be strictly democratic, for the election must be made by the existing Fellows, but we come from every field of natural science and our ages vary within reasonable limits. At present our youngest Fellow is thirty-one, and Council this morning authorized the dispatch of a letter conveying the congratulations of the Society to our colleague, Mr. H. N. Ridley, whose hundredth birthday falls on December 10. We have to be constantly on the watch to avoid neglecting the claims of scientists whose work cuts across the standard classification. But the machinery is elastic: I have seen it at work over a fairly long period and I have always been impressed by the individual capacity for honest judgment which goes to the formation of a collective opinion on scientific merit. It is certainly a responsibility which we do not take lightly, and it is right that it should occupy much of our time in the early months of the year. Whatever else we should be doing, this is time well spent.

But nowadays the Society has many other things to do, and I am not sure that we have evolved the systerm of self-government which enables us to give adequate consideration to all of them. Election to our Council must be governed by the need to keep a balanced representation of different branches of science. Council would soon become ineffective if its numbers were expanded to keep pace with every new development; but with a body of only sixteen members, apart from the Officers, to represent our 560 Fellows, it is naturally difficult for more than a small proportion of the Society to gain any insight into the way in which its business is conducted. For those who are chosen to serve on the Council the volume of business to be decided must often seem far too great for meetings which can rarely last much longer than $1 \frac{1}{2}$ hours and occur only twelve times a year. Naturally a great deal of the work falls on the Secretaries, who must be prepared with advice on many of the matters which do not involve major issues; but even though the Council is willing to accept this advice without lengthy discussion, there are certain important decisions to be made at each meeting, and it is very difficult to find the additional time needed for the discussion of more general problems. With the present growth of scientific effort, problems of general policy are bound to be in our minds, and I know that the President must often have seemed unduly repressive when there is a long agenda and the Council meeting must be ended in time for the Ordinary meeting of the Society.

I have no solution to offer which would not involve more time spent in committee rooms and less in our laboratories. That may be a burden which we must accept. But I would urge the Society that it should act only as an adviser, and should not be willing to accept the kind of detailed administrative work which it is sometimes asked to undertake. Our difficulties arise from the fact that our responsibilities have grown. We must be constantly on guard to see that we have the leisure to survey them.

My successor with his new Officers and Council will have troublesome decisions to face ; but we need not fear that the Society will ever be in danger of becoming less representative of science as a whole or less important in the affairs of the country. Your President becomes increasingly aware of its importance as he learns the duties of his office. Some of them are onerous; but it would be absurd to suggest that he has a thankless task in representing our great and ancient Society. So in conclusion all that I need add is the earnest hope that my successor will find his position as enjoyable as I have found it during these past five years. 